\section{Conference}

\section{Givcuit}

\title{
Electronic dissemination of full-text journal articles
}

\author{
By Nicholas C. Burckel
}

\section{CARL, Elsevier, and EBSCO share their plans for electronic publish- ing and document delivery}

A t ALA's Midwinter meeting EBSCO held another in its Executive Seminar Series, presented to directors of the Association of Research Libraries and dealing with electronic storage and dissemination of full-text journal articles. The evening's speakers were Ward Shaw, chief executive officer of CARL Systems, Inc.; Karen Hunter, vice-president and assistant to the chairman, Elsevier Science Publishers; and Tim Collins, general manager of EBSCO Publishing.

\section{Uncover 2}

Ward Shaw's opening remarks traced the recent history of Uncover 2. CARL Systems, Inc. began providing a journal table of contents service less than three years ago. Instead of having vendors mail journals directly to supplying libraries in the Denver area, under a new program called Uncover, journals are first sent to CARL's Denver office. Within 24 hours of receipt, tables of contents are entered into Uncover, an online database of nearly two million article titles from 12,000 different journals. Journals are then sent to owning libraries "shelfready" within 24 hours. The database is searchable by author, title, subject, and key word. Within the past several months CARL has unveiled Uncover 2. CARL has developed the capability of scanning articles, moving the bitmapped images over networks, and ending in a faxed copy in a user's hands within 24 hours.

Here's how it works. Library patrons pull up Uncover 2 on the terminal, search for needed articles, then are offered the option of having the article faxed to them. The online system prompts patrons through a series of screen options, allowing them to order items through a credit card, much as they might do for mail order purchases. A person is electronically contacted at a library holding the journals; the item is retrieved, scanned, and sent to Denver where it is then faxed to the user.

Shaw noted that, with the publisher's permission, CARL can retain the article in machinereadable form for subsequent distribution, reducing the time for future patrons to receive the same article to less than one hour. So far some 368 publishers have worked out agreements with CARL. The cost? The standard fee for the service is $\$ 6.50$ per article plus a copyright fee. That fee is set by the publisher and appears on the screen along with the service fee so that users know exactly how much an article will cost.

One satisfied user is the University of $\mathrm{Ha}_{-}$ waii at Manoa. Library staff took five article requests to their interlibrary loan department and found that it took an average of two weeks to obtain the needed material at an average out-of-pocket expense of $\$ 8$ per item. They submitted the same requests through Uncover 2 . One article arrived within two hours, three more in 24 hours, and the fifth in 25 hours. The average cost was roughly equal to that for ILL.

As exciting as this may sound, CARL's Shaw sees Uncover 2 as transitional. Electronic and online journals are just beginning to be tested. With networks facilitating a less structured exchange of information among researchers, even the concept of journals may be transformed.

\section{Tulip}

The future of journal publishing was very much the concern of the evening's second speaker, Karen Hunter of Elsevier. Hunter reported on 
four different ways publishers are dealing with electronic storage and use of journal articles. For a number of years science publishers have been distributing full text without graphics electronically through STN. Because of the loss of important graphics, however, users see such access as a surrogate, not a substitute for the complete article.

Another method of distribution has involved CD-ROM collections of bit-mapped articles from selected journals, an approach employed by UMI. Adonis is a document delivery service sold on subscription, employing a similar approach. It is a CD-ROM collection of articles from 360 biomedical journals from 30 different publishers, and the subscription price is about ten percent of the list price of the paper copy of the journals plus a charge for each copy made.

Publishers may also grant permission to other organizations that request electronic access to provide document delivery. Although not many large publishers have yet agreed to provide that access, Elsevier's Hunter thinks that will change. She cited Uncover 2 as one successful collaboration. Publishers are also usually willing to permit corporate use of the electronic information because they are unlikely to extend access beyond the company to competitors. Some universities, such as Comell and Carnegie-Mellon, have also succeeded in making experimental arrangements with publishers.

Elsevier is considering another approach. Its Tulip (The University Licensing Program) proposal would load the page images of 42 journals in material science onto an Internet server for network distribution to a dozen participating universities. The universities would then be licensed to redistribute the articles throughout their campuses using whatever local system and procedures seemed appropriate to their users. From the publishers' point of view the major issues are not technical, but legal and economic. Such an unbundling of services involves significant risk. A decision is expected later this year.

\section{EBSCO's perspective}

Rounding out the program, EBSCO vice-president Tim Collins provided the perspective of a publisher and subscription agent. EBSCO produces Academic Abstracts, providing abstracts for 10,000 general reference magazines, as well as serving as a subscription agent for libraries.

Collins thinks the biggest change in the industry has been the phenomenal growth in in- formation with its implications for publishers, libraries, and researchers. Libraries are looking for ways to control the rising cost of acquiring the incredible surge in published information. Increasingly they are relying on electronically produced abstracts from which patrons select those articles they wish to examine. Those articles are then purchased through a document delivery system, obviating the need to buy, catalog, bind, and shelve paper copies of entire journals.

As more institutions choose to cancel subscriptions and substitute document delivery, publishers are considering how to price their products and services. Their approach, according to Collins, has been more intuitive than scientific. If the publisher of information in electronic form believes that information will be infrequently consulted, he will probably charge a high initial purchase price in order to recover costs. If, however, he believes his product will be consulted very often, he will probably be inclined to provide the product as inexpensively as possible, relying on per-use charges to recover his investment. After setting charges based on intuition, publishers then measure the effect of that pricing policy and revise it as experience dictates. EBSCO has used this approach in marketing hundreds of its $\mathrm{CD}$ products.

EBSCO's seminar, attended by approximately 60 librarians, concluded with a brief question and answer period.

\section{(Beaubien cont. from page 321)}

to understand these immensely difficult forcesare ready at all levels of our profession to make wise decisions based on fact rather than illusion. I want to confer with people who will see all sides of any problem, who have the creativity and energy to think new thoughts, who can motivate those around them, yet who will accept real constraints and be willing to change their opinions when necessary. Those are my personal reasons for advocating recruitment. I hope you will share them.

This has been an immensely exciting year for me, one I will never forget. As it winds down, I want to thank Althea Jenkins, Cathleen Bourdon, Mary Ellen Davis, Sheila Delacroix, and Margaret Myers and all their very capable staff for unfailing support. The association is in excellent hands, and I am honored to have worked with its staff and with so many members to accomplish our common goals. 